08

\title{
Микроструктура и элементный состав наноразмерных порошков и пленок редкоземельных ферритов-гранатов на основе $\mathrm{Sm}_{3} \mathrm{Fe}_{5} \mathrm{O}_{12}$
}

\author{
() Н.И. Цидаева, ${ }^{1}$ А.Т. Накусов, ${ }^{1}$ С.А. Хайманов, ${ }^{1}$ А.К. Хубаев, ${ }^{1}$ Л.M. Кубалова, ${ }^{2}$ W. Wang ${ }^{3}$ \\ ${ }^{1}$ Научно-образовательный центр естественных наук Северо-Осетинского \\ государственного университета им. К.Л. Хетагурова, \\ 362025 Владикавказ, Россия \\ ${ }^{2}$ Кафедра общей и неорганической химии Северо-Осетинского государственного университета, \\ 362025 Владикавказ, Россия \\ ${ }^{3}$ State Key Laboratory of Chemical Resource Engineering and School of Science, Beijing University of Chemical Technology, \\ 100029 Beijing, China \\ e-mail: tsidaevan@mail.ru shasha_nat@mail.ru
}

Поступило в Редакцию 8 мая 2019 г.

В окончательной редакции 14 июня 2019 г.

Принято к публикации 31 июля 2019 г.

Гидротермальным методом, а также методом осаждения водных растворов нитратов на поверхность подложки проведен синтез наноструктурированных порошков и пленок на основе редкоземельного феррита-граната $\mathrm{Sm}_{3} \mathrm{Fe}_{5} \mathrm{O}_{12}$. С использованием атомно-силовой микроскопии, сканирующей электронной микроскопии, рамановской спектроскопии и рентгенофазового анализа исследованы топология поверхности и фазовый состав полученных образцов. Оценены формы и размеры частиц, проанализированы структурные особенности порошков и пленок, исследованы химический состав и кристаллические структуры синтезированных образцов. Исходя из совокупности полученных результатов, показано, что материалы на основе $\mathrm{Sm}_{3} \mathrm{Fe}_{5} \mathrm{O}_{12}$ благодаря своим структурным особенностям и физико-химическим параметрам могут найти применение в качестве фильтров для очистки промышленных сточных вод.

Ключевые слова: редкоземельные ферриты-гранаты, наноструктурированные порошки, топология поверхности, атомно-силовая микроскопия, комбинация АСМ и конфокальной рамановской спектроскопии.

DOI: 10.21883/JTF.2020.02.48823.193-19

\section{Введение}

Рост городов, бурное развитие промышленности, интенсификация сельского хозяйства и ряд других факторов стали причиной возникновения важной экологической проблемы, а именно загрязнения водных ресурсов планеты такими элементами, как красители и тяжелые металлы, что привело к сокращению источников пресной воды, а также негативно повлияло на здоровье людей $[1,2]$. Для решения этой проблемы необходима разработка новых и модернизация уже использующихся методов очистки сточных вод. Основными параметрами, требующими улучшения при разработке данных методов, являются эффективность очистки, возможность поглощения широкого спектра загрязняющих веществ и стоимость.

Базовыми методами очистки, использующимися в последние годы, являются биодеградация, ионообмен, химическое окисление, нанофильтрация и адсорбция [3-6]. Среди всех вышеуказанных методов адсорбция является одним из самых эффективных (от 92 до 99\% в зависимости от загрязняющего вещества), экономичных и простых в эксплуатации [7]. Существенным фактом, влияющим на качество очистки при использовании данного метода, является выбор адсорбента, поскольку применяемые материалы, такие как активированный уголь или биосорбенты, обладают невысокими адсорбционными свойствами, возможностью устранения только узкого спектра загрязняющих веществ, высокой стоимостью и сложным процессом утилизации $[8,9]$.

В ряду материалов, используемых в качестве активных элементов фильтров для очистки сточных вод, наиболее привлекательными для исследования и последующего применения являются редкоземельные ферриты-гранаты. Данные материалы (общая формула $\mathrm{R}_{3} \mathrm{Fe}_{5} \mathrm{O}_{12}$ где $\mathrm{R}$ - атом редкоземельного металла) представляют уникальную группу, которая в последние годы является одной из наиболее перспективных для исследования как в фундаментальной, так и в прикладной областях науки $[10,11]$. Это обусловлено магнитными, магнитооптическими и магниторезонансными свойствами этих материалов [12-14]. Благодаря этим свойствам уже реализовано применение различных модификаций редкоземельных ферритов-гранатов в качестве основных элементов магнитооптических систем хранения информации, волноводных оптических изоляторов, микроволновых устройств, сенсоров для регистрации магнитных полей с высокой чувствительностью и др. [15-17].

Однако, несмотря на вышеперечисленные параметры и связанные с ними области применения, наибольший интерес в настоящее время проявляется к исследованию адсорбционных свойств этих материалов, что обуслов- 
лено их особенностями, а именно большой площадью адсорбирующей поверхности, магнитными свойствами наночастиц и простыми процессами регенерации истощенного адсорбента с последующим его использованием $[18,19]$.

Основными факторами, влияющими на параметры и свойства $\mathrm{R}_{3} \mathrm{Fe}_{5} \mathrm{O}_{12}$ и соответственно области их практического применения, являются микроструктура и состав. Исследованию именно этих параметров посвящено обширное количество работ различных научных коллективов [20-24].

Актуальность работы определяется следующими обстоятельствами:

1. Оптимизация процессов и подбор параметров синтеза для создания материалов с заданной топологией структуры и определенного элементного состава существенно увеличит адсорбционные свойства редкоземельных ферритов-гранатов, что позволит разработать активные элементы фильтров с высокой степенью очистки промышленных сточных вод;

2. Благодаря широкому кругу физико-химических методов исследования полученные результаты изучения структурных особенностей и элементного состава порошков и пленок на основе $\mathrm{Sm}_{3} \mathrm{Fe}_{5} \mathrm{O}_{12}$ позволят выявить закономерности, влияющие на адсорбционные свойства материалов.

\section{1. Методы синтеза}

Синтез порошков на основе $\mathrm{Sm}_{3} \mathrm{Fe}_{5} \mathrm{O}_{12}$ осуществлялся гидротермальным методом. Суть данного метода, впервые предложенного Шафотле в 1845 г. [25], заключается в синтезе твердофазных веществ в закрытой системе при использовании воды. Доработанный и модифицированный различными учеными гидротермальный метод стал наиболее оптимальным из существующих методов синтеза редкоземельных ферритов-гранатов.

Исходные реагенты - азотнокислые соли $\mathrm{Sm}\left(\mathrm{NO}_{3}\right)_{3} \cdot 6 \mathrm{H}_{2} \mathrm{O} \quad$ и $\quad \mathrm{Fe}\left(\mathrm{NO}_{3}\right)_{3} \cdot 9 \mathrm{H}_{2} \mathrm{O} \quad(2.6$ и $\quad 4.04 \mathrm{~g}$ соответственно, рассчитанные по молярным соотношениям) - растворяли в $70 \mathrm{ml}$ дистиллированной воды. Раствор в течение $1 \mathrm{~h}$ размешивали при помощи магнитной мешалки (при $6000 \mathrm{rpm})$. В ходе всего процесса размешивания в раствор добавлялась щелочь $\mathrm{NaOH}$ в количестве $14 \mathrm{~g}$. Формирование окончательной структуры ферритов-гранатов осуществлялось путем температурной обработки раствора в течение $12 \mathrm{~h}$, температура варьировалась от 150 до $240^{\circ} \mathrm{C}$.

Для получения $\mathrm{pH}=7$, проводилась промывка раствора деионизированной водой. Для максимального осаждения полученного феррита-граната раствор центрифугировали (3-5 min) с добавлением этанола $(25-30 \mathrm{ml})$.

Удаление остаточных продуктов реакции из синтезированного порошка осуществлялось путем просушки в течение $10 \mathrm{~h}$ при температуре $80^{\circ} \mathrm{C}$.
Схематический процесс синтеза $\mathrm{Sm}_{3} \mathrm{Fe}_{5} \mathrm{O}_{12}$ гидротермальным методом можно представить в виде последовательности химических реакций (1) и (2):

$$
\mathrm{Fe}\left(\mathrm{NO}_{3}\right)_{3} \cdot 9 \mathrm{H}_{2} \mathrm{O}+\mathrm{Sm}\left(\mathrm{NO}_{3}\right)_{3} \cdot 6 \mathrm{H}_{2} \mathrm{O}
$$

растворение в $\mathrm{H}_{2} \mathrm{O}$, добавление $\mathrm{NaOH}$ p-p.

$$
\begin{gathered}
5\left[\mathrm{Fe}\left(\mathrm{NO}_{3}\right)_{3} \cdot 9 \mathrm{H}_{2} \mathrm{O}+3\left[\mathrm{Sm}\left(\mathrm{NO}_{3}\right)_{3} \cdot 6 \mathrm{H}_{2} \mathrm{O}\right]\right. \\
+24 \mathrm{NaOH} \rightarrow 24 \mathrm{NaOH}+3 \mathrm{Sm}(\mathrm{OH})_{3 \downarrow} \\
+5 \mathrm{Fe}(\mathrm{OH})_{3 \downarrow}++63 \mathrm{H}_{2} \mathrm{O}, \\
3 \mathrm{Sm}(\mathrm{OH})_{3}+5 \mathrm{Fe}(\mathrm{OH})_{3} \rightarrow \mathrm{Sm}_{3} \mathrm{Fe}_{5} \mathrm{O}_{12}+12 \mathrm{H}_{2} \mathrm{O}_{\uparrow} .
\end{gathered}
$$

Более подробно идентичные процессы синтеза и схема установки для синтеза как редкоземельных ферритов-гранатов, так и других веществ гидротермальным методом описаны в работах $[8,26]$.

В ходе работы в качестве образцов для исследования также использовались наноструктурированные пленки на основе $\mathrm{Sm}_{3} \mathrm{Fe}_{5} \mathrm{O}_{12}$. Формирование пленок осуществлялось путем нанесения растворов $\mathrm{Sm}_{3} \mathrm{Fe}_{5} \mathrm{O}_{12}+\mathrm{HNO}_{3}$ на поверхность предварительно обработанной подложки на основе $\mathrm{Al}_{2} \mathrm{O}_{3}$. Для улучшения адгезии пленки и подложечного материала, а также удаления остаточных нитратов, находившихся в растворе, образцы подвергались температурной обработке при $80^{\circ} \mathrm{C}$ с временем выдержки $t_{\exp }=1 \mathrm{~h}$ и давлении $P=0.07 \mathrm{MPa}$. Аналогичным методом пленки получали также авторы работы [27].

В случае наноразмерных пленок влияние на их структуру оказывает подложечный материал, в связи с чем выбор подложки, на которой будут формироваться пленки, является важным фактором. Выбор подложки был обусловлен свойствами $\mathrm{Al}_{2} \mathrm{O}_{3}$, а именно сильно развитой микроструктурой поверхности, диэлектрическими свойствами и отсутствием магнитных свойств [28].

\section{2. Методы исследований}

Химический и фазовый состав синтезированных порошков исследовался методом рентгенофазового анализа (РФА) при помощи дифрактометра фирмы Bruker D8 Advance. Эксперимент проводился с помощью вертикального гониометра на медном излучении с длиной волны $\mathrm{Cu} K_{\alpha}=1.54 \AA$ в интервале углов $\theta / 2 \theta=10-90^{\circ}$.

Идентификация фаз и кристаллической структуры осуществлялась по соотношению интенсивностей и углов характеристических пиков этих фаз на дифрактограммах. Для сравнения и подтверждения полученных результатов использовались базы данных рентгеновских дифрактограмм, находящиеся в открытом доступе, а также результаты, приведенные в работах [20-22].

Особенности поверхностной топологии, структура и размеры первичных частиц исследуемых порошков и пленок изучались с применением электронномикроскопических методов, таких как сканирующая 
электронная микроскопия (СЭМ) и атомно-силовая микроскопия (АСМ). Исследования проводились на сканирующем электронном микроскопе S4700 фирмы Hitachi, a также зондовой нанолаборатории NTEGRA Spectra фирмы NT-MDT. АCM-исследования проводились с использованием кантилеверов VIT_P с кремниевой иглой, имеющей радиус закругления $10 \mathrm{~nm}$.

NTEGRA Spectra со спектрометром комбинационного рассеяния Solar TII, представляющая собой единый модуль с компьютерным управлением, использовалась также для определения спектров рамановского рассеяния образцов. Источником возбуждения являлся $\mathrm{He}-\mathrm{Ne}-$ лазер с длиной волны $\lambda=633 \mathrm{~nm}$. АСМ-исследование поверхностной топологии и спектроскопия проводились одновременно на одном и том же участке образца, что позволило в любой точке площади сканирования наблюдать как структуру, так и элементный состав образцов.

\section{3. Результаты исследований и их обсуждение}

\section{1. Рентгенофазовый анализ}

Результаты исследования РФА порошков на основе $\mathrm{Sm}_{3} \mathrm{Fe}_{5} \mathrm{O}_{12}$ представлены в виде дифрактограмм на рис. 1. В ходе проведения эксперимента использовались порошки, синтезированные при различных температурах, а именно 240, 200, 180 и $150^{\circ} \mathrm{C}$. Обработка порошков при температурах свыше $240^{\circ} \mathrm{C}$ являлась нецелесообразной, поскольку точка Кюри для данного
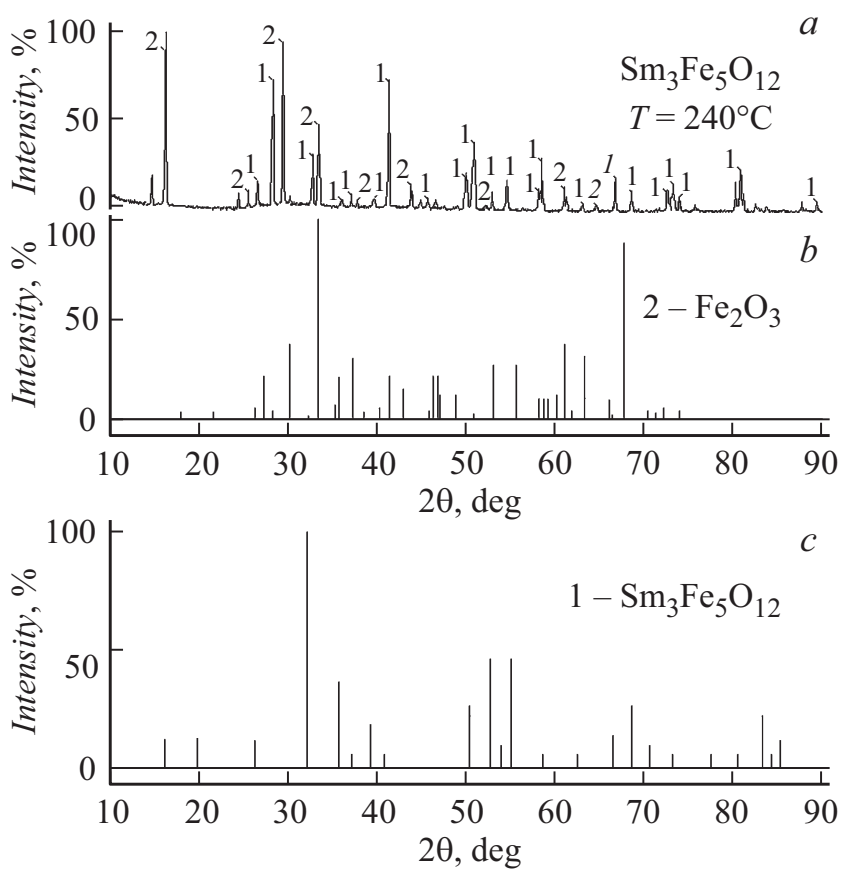

Pис. 1. Дифрактограммы порошка $\mathrm{Sm}_{3} \mathrm{Fe}_{5} \mathrm{O}_{12}$, синтезированного при температуре $T=240^{\circ} \mathrm{C}(a)$, и дифрактограммы $\mathrm{Fe}_{2} \mathrm{O}_{3}(b)$ и $\mathrm{Sm}_{3} \mathrm{Fe}_{5} \mathrm{O}_{12}(c)$, представленные в базах данных.

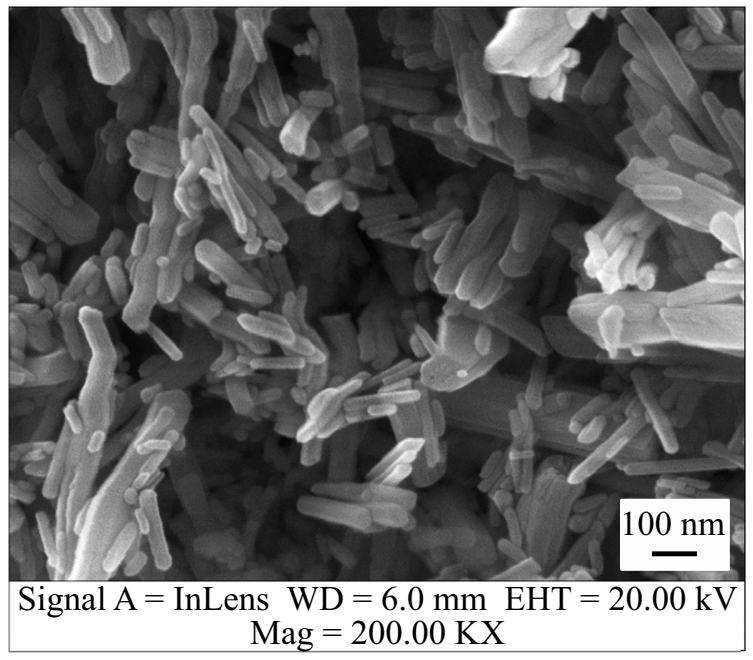

Рис. 2. СЭМ - изображение порошка на основе редкоземельного феррита самария.

материала составляет $T_{\mathrm{C}} \approx 286^{\circ} \mathrm{C}$ и соответственно при более высоких температурах порошки $\mathrm{Sm}_{3} \mathrm{Fe}_{5} \mathrm{O}_{12}$ теряют свои ферромагнитные свойства $[29,30]$.

Исходя из представленных изображений, можно отметить следующее:

- изменение температурного режима в процессе синтеза в пределах от 150 до $240^{\circ} \mathrm{C}$ существенно не влияет на структуру порошков $\mathrm{Sm}_{3} \mathrm{Fe}_{5} \mathrm{O}_{12}$, на всех полученных дифрактограммах наблюдаются пики, соответствующие кубической структуре феррита-граната с редкоземельным элементом Sm;

- отдельных рефлексов на дифрактограммах, соответствующих элементам $\mathrm{Sm}, \mathrm{Fe}$ и $\mathrm{O}_{2}$, не наблюдается, что подтверждает образование в ходе синтеза материала $\mathrm{Sm}_{3} \mathrm{Fe}_{5} \mathrm{O}_{12}$;

- кроме пиков $\mathrm{Sm}_{3} \mathrm{Fe}_{5} \mathrm{O}_{12}$ дифрактограммы возможно содержат рефлексы фазы $\mathrm{Fe}_{2} \mathrm{O}_{3}, \mathrm{Sm}_{2} \mathrm{O}_{3}$ и $\mathrm{SmFeO}_{3}$, что подтверждается значениями баз данных (рис. 1), а также результатами, представленными в работах $[21,22]$;

- полученные нами дифрактограммы не идентичны результатам, представленным другими авторами [21,22], а также некоторым дифрактограммам из баз данных. Данный факт связан с величиной температуры синтеза, максимум которой в нашей работе составлял $240^{\circ} \mathrm{C}$, тогда как у других исследователей температура при синтезе варьировалась от 500 до $1000^{\circ} \mathrm{C}$. Причина, по которой нами был выбран данный температурный интервал, связана с величиной температуры Кюри, т.е. нежелательностью потери магнитных свойств исследуемых материалов.

\section{2. СЭМ и $\mathrm{ACM}$}

Применение СЭМ и АСМ позволило исследовать общий характер структуры всей поверхности объекта 

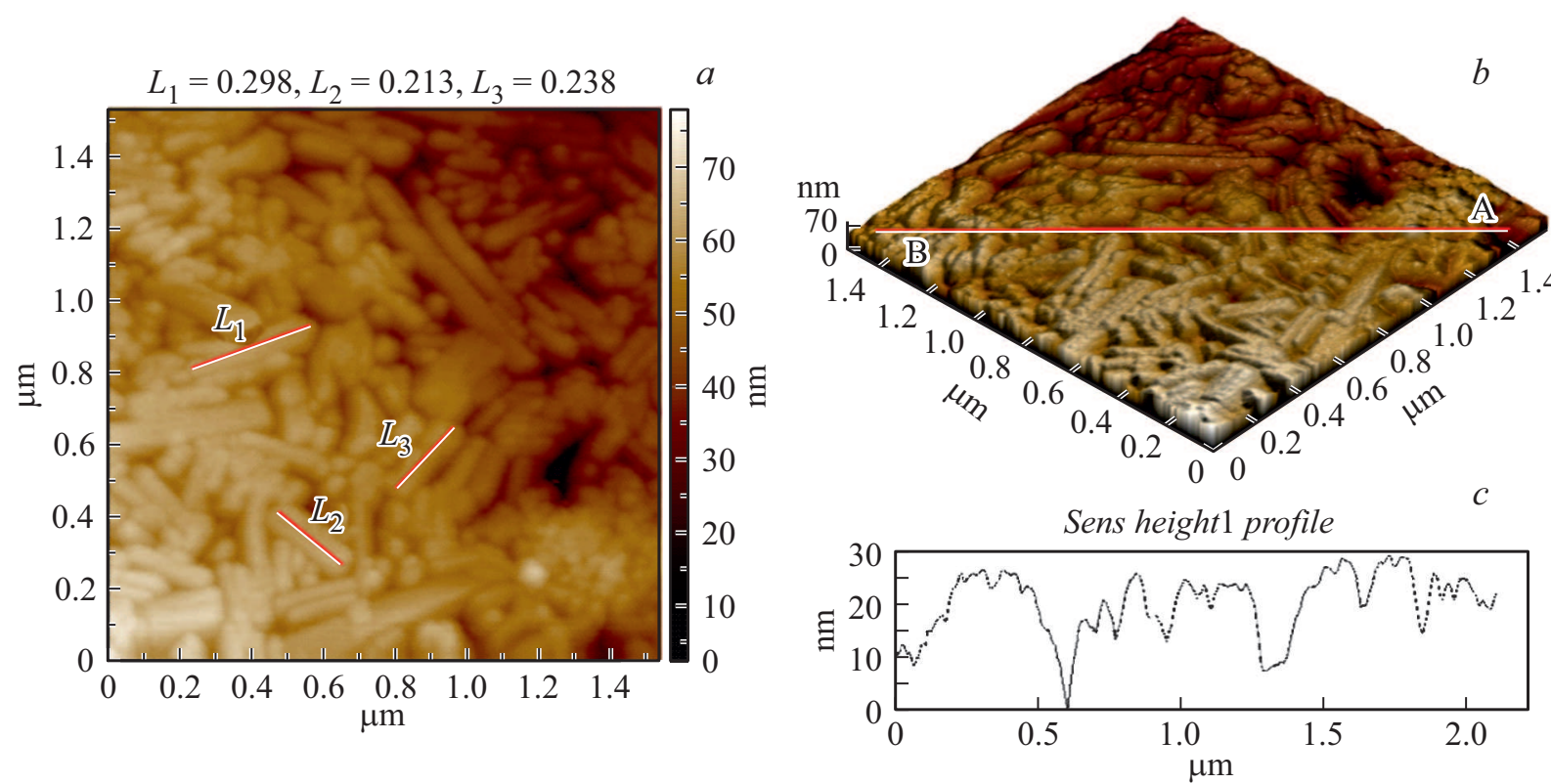

Рис. 3. $\mathrm{ACM}-(a)$ и квазитрехмерное $(b)$ изображение топологии поверхности участка $1.5 \times 1.5 \mu$ m спрессованного порошка редкоземельного феррита самария, а также перепады высот в направлении $A-B(c)$.
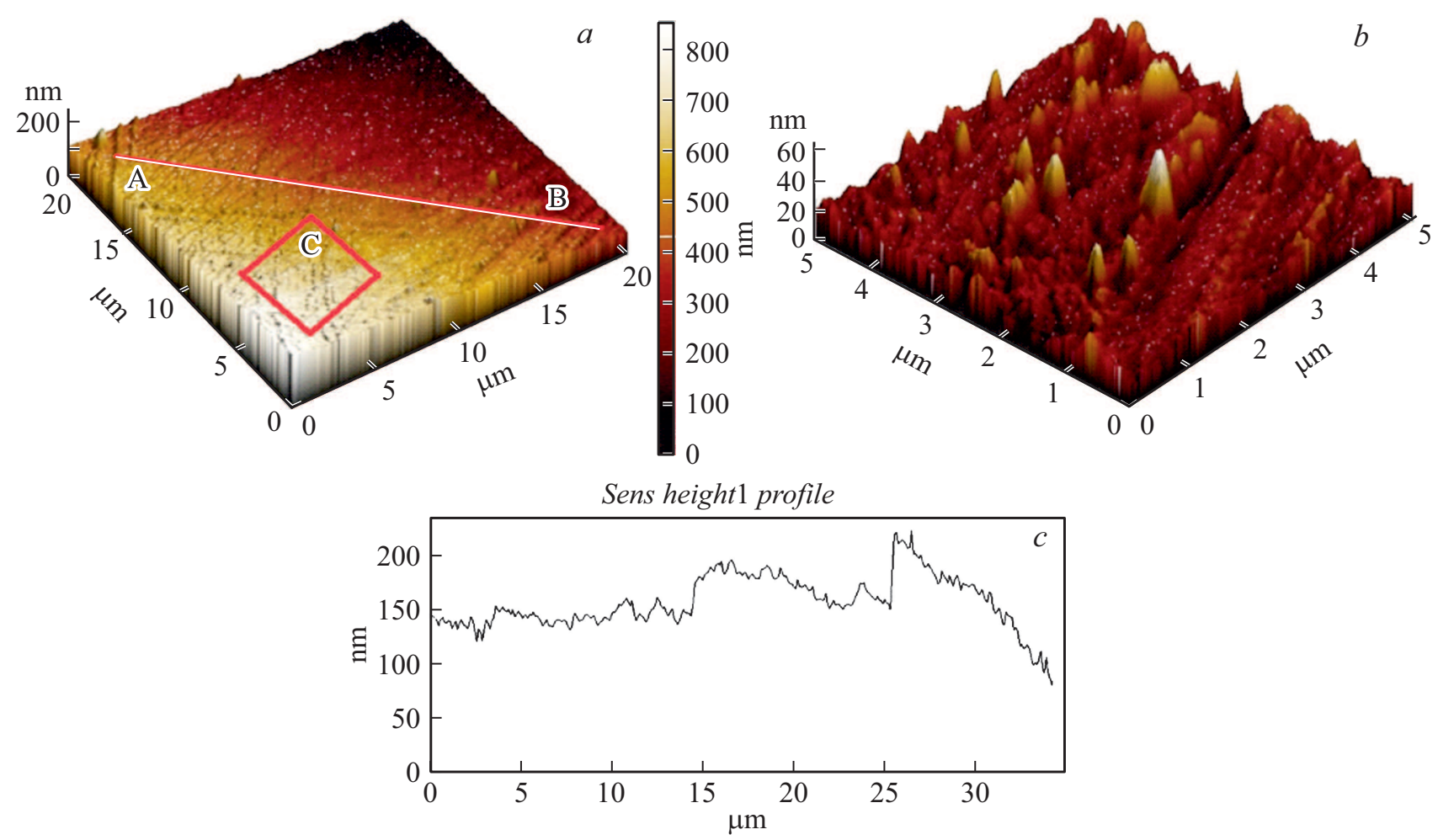

Рис. 4. Квазитрехмерное изображение топологии поверхности участков $20 \times 20(a)$ и $5 \times 5(b) \mu$ m подложки на основе $\mathrm{Al}_{2} \mathrm{O}_{3}$, а также перепад высот в направлении отрезка $A-B(c)$. 

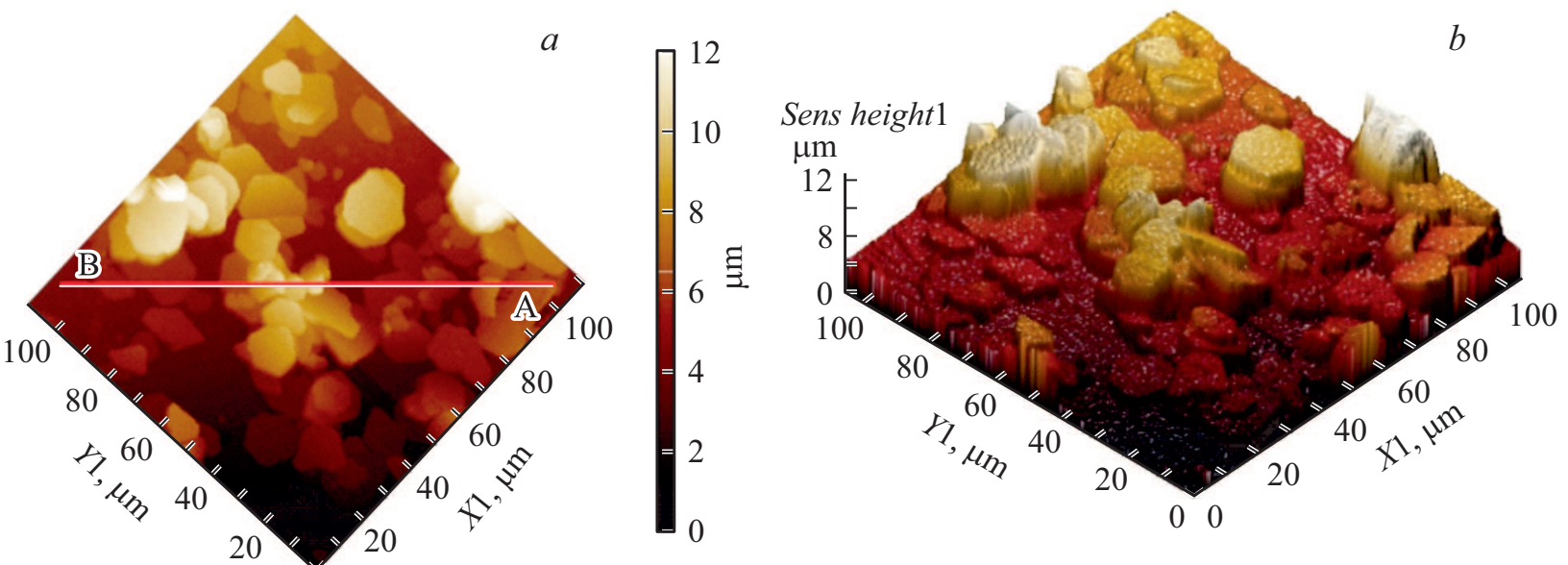

00

Sens height1 profile

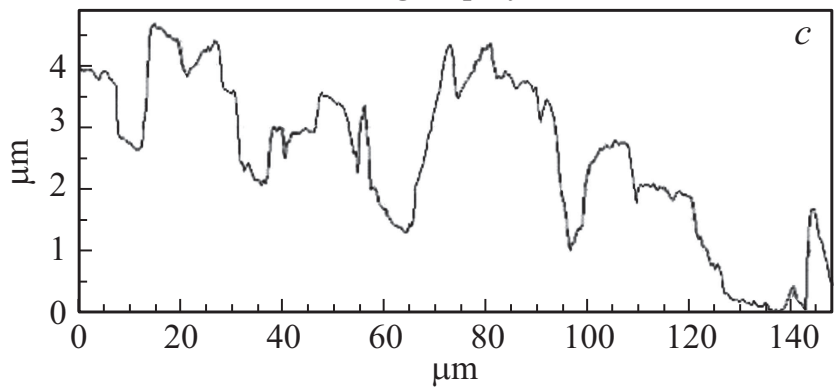

Рис. 5. АСМ- $(a)$ и квазитрехмерное $(b)$ изображения топологии поверхности пленки $\mathrm{Sm}_{3} \mathrm{Fe}_{5} \mathrm{O}_{12}$, а также перепад высот пленки в направлении отрезка $A-B(c)$.

при малых увеличениях и детально изучить любой, вызвавший интерес участок при больших увеличениях.

Результаты, полученные с помощью СЭМ, представлены на рис. 2.

На СЭМ-изображениях наблюдается пористая неориентированная структура, состоящая из частиц, вытянутых в одном направлении, с горизонтальными размерами, изменяющимися в пределах от 60 до $800 \mathrm{~nm}$.

Наиболее информативны результаты, полученные методом АCM, позволяющей изучать образцы в воздушной атмосфере с разрешением на атомарном уровне [31].

При исследовании методом АСМ в качестве объектов использовались порошки, спрессованные в виде таблеток (величина внешнего давления при прессовании составляла 2 тонны), и пленки совместно с подложкой, на которой они были сформированы. Образцы в виде таблеток были необходимы из-за технологических особенностей метода АСM, а именно поверхность образцов должна быть достаточно ровной, поскольку поверхностные нерегулярности (большие и резкие перепады высот) выбивают из рабочего режима колеблющийся кантилевер, что не позволяет качественно провести эксперимент.

Топология поверхности, характерная для порошков $\mathrm{Sm}_{3} \mathrm{Fe}_{5} \mathrm{O}_{12}$, представлена в виде АCМ- и квазитрехмерных изображений на рис. 3.
На АСМ-изображениях видны вытянутые в одном направлении без определенной ориентации частицы с размерами, изменяющимися в интервале от 60 до $800 \mathrm{~nm}$. Топология поверхности хаотична, неориентирована и состоит из частиц, объединяющихся в агломераты. Перепад высот на участке $1.5 \times 1.5 \mu \mathrm{m}$ в направлении $A-B$ составляет порядка $30 \mathrm{~nm}$ (рис. 3, $)$ ).

Выбор участков сканирования был обусловлен размерами частиц исследуемых порошков, использование более или менее обширных участков не позволило бы качественно оценить форму и размеры частиц.

Для исследования пленок на основе $\mathrm{Sm}_{3} \mathrm{Fe}_{5} \mathrm{O}_{12}$ образцы предварительно необходимо было сформировать на подложке из $\mathrm{Al}_{2} \mathrm{O}_{3}$. Структура подложечного материала на основе $\mathrm{Al}_{2} \mathrm{O}_{3}$ при сканировании на участках $20 \times 20$ и $5 \times 5 \mu \mathrm{m}$ (рис. $4, a, b$ ) состоит из зерен размерами 50-200 nm с перепадами высот $200 \mathrm{~nm}$ в направлении отрезка $A-B$ (рис. 4,c). Относительно невысокий перепад высот объясняется предварительной обработкой поверхности подложки (шлифование). Полученные параметры подложки в целом являлись удовлетворительными для их дальнейшего использования в ходе настоящей работы.

Результаты исследования структурных особенностей поверхности наноразмерных пленок представлены на рис. 5. Визуализация мелких деталей поверхностных слоев пленок позволяет отметить закономерность, при 


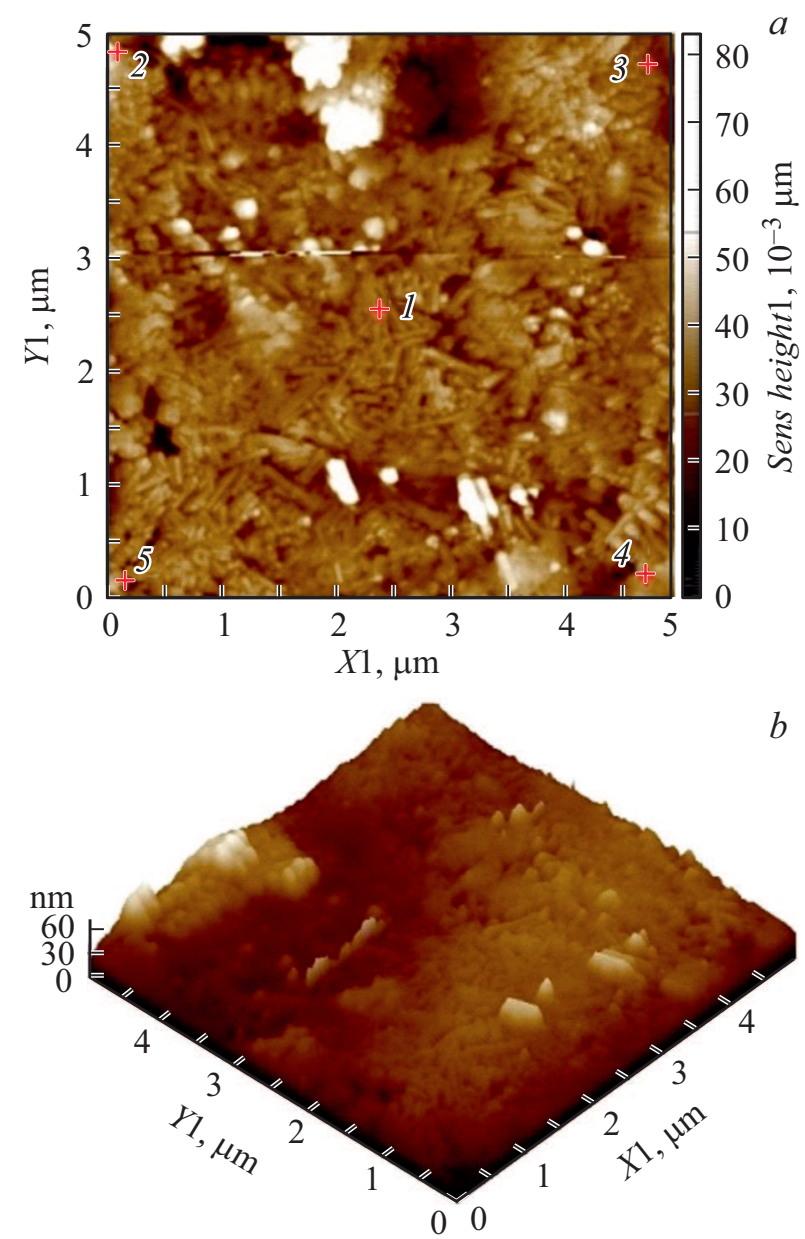

$a$

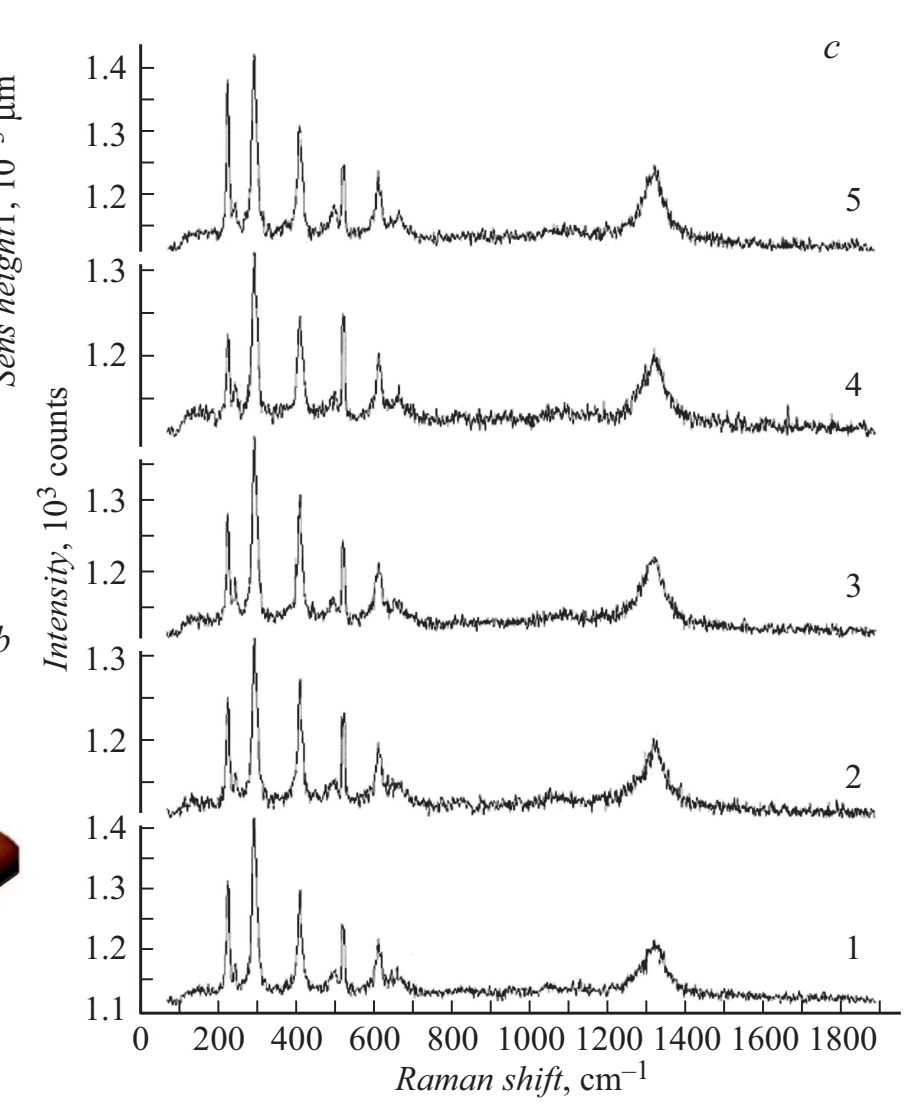

Рис. 6. АСМ- $(a)$ и квазитрехмерное $(b)$ изображения топологии поверхности участка $5 \times 5 \mu$ m спрессованного порошка $\mathrm{Sm}_{3} \mathrm{Fe}_{5} \mathrm{O}_{12}$, а также рамановские спектры, снятые в точках $1-5(c)$.

которой первичные частицы, формирующие пленку, объединились в агломераты округлой формы и размерами, в горизонтальном направлении варьирующимися в пределах от 5 до $15 \mu \mathrm{m}$. В дальнейшем сформированные агломераты за счет магнитных свойств исследуемого материала притягиваются друг к другу. За счет притягивания и наложения друг на друга агломератов максимальная величина перепада высот синтезированных пленок достаточно высока и составляет по всей площади сканируемой поверхности $12 \mu \mathrm{m}$ (рис. $5, a$ ), а в направлении отрезка $A-B-5 \mu \mathrm{m}$ (рис. $5, c)$.

Характерные для пленок агломераты не наблюдаются на АСМ-изображениях порошков (таблетки), поскольку образцы при формировании не подвергались прессованию, т.е. при создании таблеток из порошков силы механического воздействия оказались больше, чем магнитное взаимодействие между частицами, что и привело к разрушению агломератов.

Образование агломератов происходит в течение определенного времени, данный факт подтверждается СЭМизображениями (рис. 2) частиц порошка $\mathrm{Sm}_{3} \mathrm{Fe}_{5} \mathrm{O}_{12}$, которые были сделаны непосредственно после синтеза без всякого внешнего воздействия на образцы. Топология поверхности, форма и размеры частиц, полученные СЭМ и АСМ методиками, идентичны друг другу, что подтверждает истинность полученных результатов.

\section{3. Рамановская спектроскопия}

В процессе исследования материалов также применялась дисперсионная рамановская спектроскопия, представляющая собой спектроскопию для наблюдения за неэластично рассеянным светом, позволяющая идентифицировать вибрационные состояния (фононы) молекул [32].

По сравнению с другими методами, например, ИКФурье и спектроскопией ближнего ИК, рамановская спектроскопия не требует специальной подготовки образца и нечувствительна к полосам поглощения, поскольку рамановский эффект наблюдается в рассеянном свете от образца, а не в спектре поглощения образцом света [33].

Результаты комбинированного применения методов ACM и рамановской спектроскопии к исследованию 

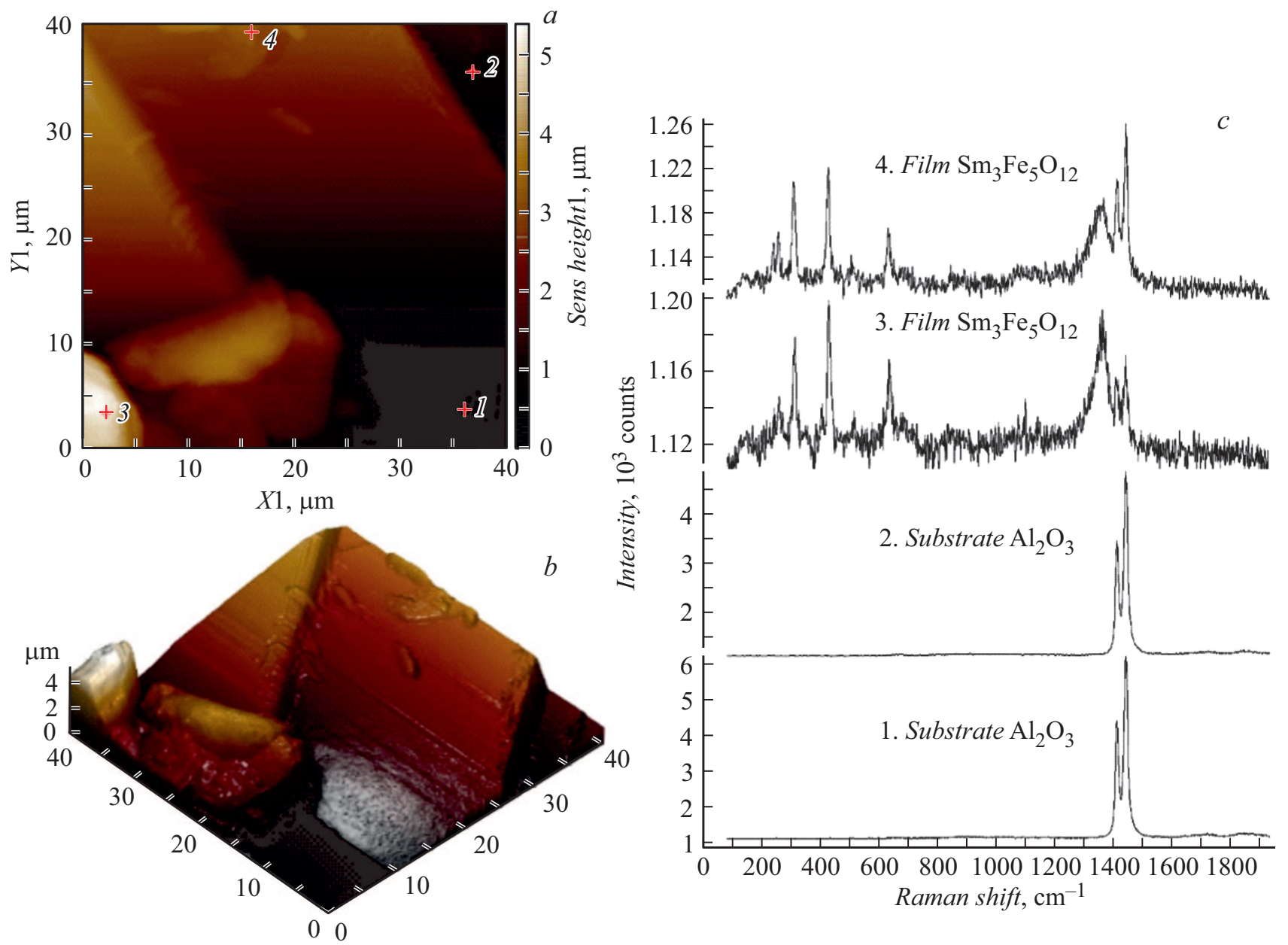

Рис. 7. АСМ- $(a)$ и квазитрехмерное $(b)$ изображения топологии поверхности пленки $\mathrm{Sm}_{3} \mathrm{Fe}_{5} \mathrm{O}_{12}$, сформированной на подложке $\mathrm{Al}_{2} \mathrm{O}_{3}$, и спектры рамановского рассеяния, снятые в точках 1-4 (c).

порошков (таблетки) и пленок $\left(\mathrm{Sm}_{3} \mathrm{Fe}_{5} \mathrm{O}_{12}\right.$ на $\left.\mathrm{Al}_{2} \mathrm{O}_{3}\right)$ представлены на рис. 6 и 7.

Исследование проводилось в различных точках поверхности образцов. Во всех исследуемых точках (1-5) пики спектров рамановского рассеяния соответствуют материалу $\mathrm{Sm}_{3} \mathrm{Fe}_{5} \mathrm{O}_{12}$ (рис. 6). В различных точках интенсивность спектров изменяется незначительно. Сопоставление полученных спектров со справочными данными $[34,35]$ и результатами работы [20] показали идентичность полученных и сравниваемых спектров.

Исходя из анализа данных, относящихся к пленке $\mathrm{Sm}_{3} \mathrm{Fe}_{5} \mathrm{O}_{12}$, сформированной на подложке из $\mathrm{Al}_{2} \mathrm{O}_{3}$, которые представлены на рис. 7, можно отметить следующее:

- видна развитая поверхность подложки, на которой наблюдаются начальные стадии формирования пленок;

- спектры рамановского рассеяния, снятые в точках 1 и 2, соответствуют пикам оксида алюминия и подтверждают состав подложечного материала, а спектры, снятые в точках 3 и 4 , соответствуют $\mathrm{Sm}_{3} \mathrm{Fe}_{5} \mathrm{O}_{12}$.

Одновременное использование АСМ и рамановской спектроскопии в ходе проведения исследований откры- вает широкие возможности при изучении материалов, комбинированный метод изучения как формы, так и элементного состава первичных частиц, позволяет выявлять исследуемое вещество в его окружении и контролировать чистоту синтезированного материала.

\section{Выводы}

Образцы, синтезированные гидротермальным методом, образованы из мелкокристаллических конгломератов с размерами частиц от 60 до $800 \mathrm{~nm}$. Наблюдается хаотическая морфология. Пористая мелкокристаллическая неориентированная структура порошков в совокупности с магнитными свойствами материала может быть с успехом использована при изготовлении активных элементов фильтров для очистки промышленных сточных вод.

Изменение температурного режима в интервале до 150 до $240^{\circ} \mathrm{C}$ в ходе синтеза не влияет на структуру исследуемых материалов. При любых значениях температуры в обозначенном интервале по данным РФА присутствует кубическая структура порошков. 
Визуально на основании данных АCM показаны магнитные свойства первичных частиц $\mathrm{Sm}_{3} \mathrm{Fe}_{5} \mathrm{O}_{12}$, характеризующиеся на начальном этапе формирования объединением в агломераты и дальнейшим соединением агломератов друг с другом.

Применение комбинации методик СЭМ, АСМ и спектроскопии рамановского рассеяния позволяет проводить анализ формы и состава микрочастиц для получения информации о наличии примесей и возможном загрязнении исследуемого материала.

\section{Заключение}

Результаты, представленные в работе, являются начальным этапом большой исследовательской работы. Основными направлениями, предполагаемыми для дальнейшего развития представленной темы, являются:

- изучение влияния изменения температурной обработки и количества щелочи в процессе гидротермального синтеза на топологические особенности и свойства ферритов-гранатов;

- подбор оптимальных параметров синтеза и исследования ферритов-гранатов с различными редкоземельными материалами, в частности $\operatorname{Pr}$ и Er;

- изучение магнитных и адсорбционных свойств синтезированных материалов;

- оптимизация методики определения примесей в исследуемом материале с применением СЭМ, АСМ и спектроскопии рамановского рассеяния;

- создание фильтров с высокой степенью очистки промышленных сточных вод.

\section{Благодарности}

Работа выполнена с применением научно-исследовательского оборудования Научно-образовательного центра естественных наук Северо-Осетинского государственного университета, а также Государственной основной лаборатории химической ресурсной инженерии пекинского университета химической технологии.

\section{Конфликт интересов}

Авторы заявляют, что у них нет конфликта интересов.

\section{Список литературы}

[1] Singh J., Kalamdhad A.S. // Intern. J. Res. Chem. Environment. 2011. Vol. 1. N 2. P. 15-21.

[2] Mahurpawar M. // Intern. J. Res. Granthaalayah. 2015. Vol. 1. P. 1-7.

[3] Wang J., Liu H., Lu R., Jin J., Zhou T., Lei M. // Intern. Biodeterioration \& Biodegradation. 2012. Vol. 67. P. 73-77. DOI: https://doi.org./10.1016/j.ibiod.2011.12.003

[4] Jorgensen T.C., Weatherley L.R. // Water Research. 2003. Vol. 37. P. 1723-1728.

DOI: https://doi.org/10.1016/S0043-1354(02)00571-7
[5] Ksibi M. // Chem. Engineer. J. 2006. Vol. 119. N 2-3. P. 161165. DOI: https://doi.org/10/1016/j/cej. 2006.03.022

[6] Hassani A.H., Mirzayee R., Nasseri S., Borghei M., Gholami M., Torabifar B. // Intern. J. Environmental Sci. Technol. 2008. Vol. 5. N 3. P. 401-408.

[7] Jameel M., Dhabab A., Abbas A. // Intern. J. Engineer. Res. Appl. (IJERA). 2012. Vol. 2. N 4. P. 2076-2084.

[8] Chen R., Wang W., Zhao X., Zhang Y., Wu S., Li F. // Chem. Engineer. J. 2014. Vol. 242. P. 226-233.

[9] Rangabhashiyam S., Suganya E., Selvaraju $N$., Varghese L.A. // World J. Microbiol. Biotechnol. 2014. Vol. 30. N 6. P. 1669-1689.

[10] Adam J.D., Davis L.E., Dionne G.F., Schloemann A., Stitzer A. // IEEE Trans. Microwav. Theor. Techniq. 2002. Vol. 50. N 3. P. 721-737. DOI: $10.1109 / 22.989957$

[11] Lax B., Button K.J. McGraw-Hill. NY. 1962. 321 p.

[12] Tsidaeva N.I., Abaeva V.V., Enaldieva E.V. et al. // IEEE Transactions on Magnetics. 2014. Vol. 50. N 1. Part. 1. P. 123 129. DOI: 10.1109/TMAG.2013.2273660

[13] Tsidaeva N.I. // J. Alloys and Compounds. 2006. Vol. 408. P. 164-168. DOI: $10.1155 / 2014 / 158946$

[14] Tsidaeva N.I., Abaeva V.V., Magkoev T.T. // Acta Phys. Polonica. 2011. Vol. 121. N 1. P. 74-77. DOI: 10.12693/APhysPolA.121.74

[15] Özgür Ü., Alivov Y., Morkoç H. // J. Mater. Sci.: Mater. in Electron. 2009. Vol. 20. N 9. P. 789-834. DOI: http://dx.doi.org/10.1007/s10854-009-9923-2

[16] Mallman E.J.J., Fechine P.B.A., Sombra A.S.B., Goes J.C. // Solid State Phenomena. 2013. Vol. 202. P. 65-96. DOI: 10.4028/www.scientific.net/SSP.202.65

[17] Inoue M., Baryshev A., Takagi H. et al. // Appl. Phys. Lett. 2011. Vol. 98. P. 132511. DOI: https://doi.org/10/1063/1.3567940

[18] Gao Z., Cui F., Zeng S., Guo L., Shi J. // Microporous and Mesoporous Materials. 2010. Vol. 132. N 1-2. P. 188-195. DOI: https://doi.org/10.1016/j.micromeso.2010.02.019

[19] Viltužnik B., Lobnik A., Košak A. // J. Sol-Gel Sci. Technol. 2015. Vol. 74. N 1. P. 199-207.

[20] Li G., Hong-ming Y., Ke-ke H., Lin Y., Shao-kong L., Shouhua F. // Chem. Res. Chinese Univ. 2011. Vol. 27. N 5. P. 715-719. DOI: 1005-9040(2011)-05-715-05

[21] Opuchovica O., Kareivaa A., Mazeikab K., Baltrunas D. // J. Magn. Magn. Mater. 2017. Vol. 422. P. 425-433. DOI: $10.1016 /$ j.jmmm.2016.09.041

[22] Cfarena V.R., Ogasawara T., Pinhom S., Capitaneo J.L. // Latin American Appl. Res. 2006. Vol. 36. P. 137-140.

[23] Huang S., Shi L.R., Sun H.G., Li C.L., Chen L., Yuan S.L. // J. Alloys Compounds. 2016. Vol. 674. P. 341346. DOI: https://doi.org/10.1016/j.jallcom.2016.03.001

[24] Qadri S.B., Sanghera S., Shinn M., Wu D.H., Bussman K., Amarasinghe P. // Mater. Lett. 2017. Vol. 207. P. 25-28. DOI: http://doi.org/10.1016/j.matlet.2017.07.003

[25] Schafhäutl K.E. // Royal Bavarian Academy of Sciences. 1845. Vol. 20. P. 557-578.

[26] Wu X., Ding Z., Wang W., Song N., Khaimanov S.A., Tsidaeva N.I. // Powder Technol. 2016. Vol. 295. P. 59-68. DOI: 10/1016/J.POWTEC.2016.03.033

[27] Рамонова А.Г., Накусов А.Т., Созанов В.Г., Блиев А.П., Магкоев T.T. // ЖТФ. 2015. Т.85. № 6. С. 90-97. [Ramonova A.G., Nakusov A.T., Sozanov V.G., Bliev A.P., Magkoev T.T. // Tech. Phys. 2015. Vol. 60. N 6. P. 877-884. DOI: $10.1134 / \mathrm{S} 1063784215060195]$ 
[28] Tikhonov P.A., Nakusov A.T., Popova I.O., Konyukhov G.S. // Glass Phys. Chem. 2005. Vol. 31. N 2. P. 252-258. DOI: $1087-6596 / 05 / 3102$

[29] Belov K.P., Talalaeva E.V., Yarkho G.A. // J. Exptl. Theoret. Phys. (USSR). 1967. Vol. 25. N 6. P. 1489-1494.

[30] Smit J., Wijn H.P.J. Ferrites. Physical properties of ferromagnetic oxides in relation to their technical applications. Philips research laboratories. Philips Technical Library, 1959. $504 \mathrm{p}$.

[31] Danilov A.I. // Rus. Chem. Rev. 1995. Vol. 64. N 8. P. 818833. DOI: 10.1070/RC1995v064n08ABEH000174

[32] Raman C.V., Krishnan K.S. // Nature. 1928. Vol. 121. P. 501. DOI: //doi.org/10.1038/121501c0

[33] Landsberg G.S., Mandelstam L.I. // J. Rus. Phys. Chem. Companies. 1928. Vol. 60. P. 335.

[34] Lewis I.R., Edwards H.G.M. (Eds.) Handbook of Raman Spectroscopy. 2001. Marcel Dekker. 1080 p.

[35] Nakamoto K. Infrared and Raman spectra of inorganic and coordination compounds. John Wiley and Sons Inc., 1986. $536 \mathrm{p}$. 